\title{
The Constant of Change: Remaining Relevant in 21st Century Higher Education
}

\author{
Mandla S. Makhanya
}

\section{Illuminating Change and Transformation in Higher Education}

While the old Heraclitan adage: "The only constant in life is change" remains true, it is the scale and impact of that change that distinguishes the routine from the radical, and the evolution from the revolution. This difference is captured succinctly by Palinkas who asserts:"Change uses external influences to modify actions, but transformation modifies beliefs so actions become natural and thereby achieve the desired result" (Palinkas 2013). Higher education, in its current state of disruption, is forcing us to revisit everything that we know and believe about education, in pursuit of its continued relevance and sustainability as a "new normal".

Key contributors to the state of disruption are fundamental and influential shifts in geo-socio-economic and political practices, rampant technological and scientific innovation, a multiplicity of role players, many of whom reside outside of the traditional higher education sphere, changing views on the nature and value of knowledge and the role of the university, and compelling contextual realities such as the need (and demands) for equity, social justice and redress. If we were ever in any kind of doubt as to the urgency of the transformation, then the current COVID-19 pandemic has brought into sharp focus the current precariousness of global higher education, revealing our weaknesses and shortcomings and galvanising a collective rethinking of virtually everything that we know and do and which we regard as "education".

This essay will briefly examine four key drivers of the current transformation in higher education which will need to be addressed to ensure relevance and sustainability. These are elucidated below.

\footnotetext{
M. S. Makhanya ( $\square)$

University of South Africa, Pretoria, South Africa

e-mail: makhams@unisa.ac.za 


\section{Co-dependent, Borderless, Yet Profoundly Unequal and Conflicted Global Societies}

Gross socio-economic disparities and increasing political polarisation, even within affluent societies, are increasingly prevalent and deleterious (OECD 2015). Poverty often scaffolds on pre-existing socio-economic inequality, and the affordances of the digitisation, when it comes to access to a quality and affordable education, more especially for women, have not been significantly reflected in the lives and development of those who need it most (Bennett and Kent 2017). This picture of exclusion is growing quite rapidly to also include disadvantaged people within more affluent societies. Diarra observes appositely [that]: "Globalization does not render the world a space with clearly delineated borders, but rather a mosaic of zones of prosperity and zones of poverty which fragment and intermingle in perpetuity...." (Diarra 2004: 122).

The nexus of these forces and trends has contributed materially to the disintegration or "unbundling" (Czerniewicz 2018); of global higher education into contextual enclaves, weakening the status of universities and shifting higher education worldwide from once a public good to a benefit for those who can afford it. Technological innovation and digitisation, firmly ensconced and facilitated by a neoliberal ideology which ostensibly encourages capitalism in the form of marketized education, even where this excludes the so-called "have nots", continues to play a fundamental role in this trajectory of disintegration.

\section{The Changing Nature, Relevance and Value of Knowledge}

As growing numbers of articles attest to massive job losses and redundancies, it is unsurprising that questions are being asked about the purpose and relevance of education. Schwab and Samans predict [that] "On average, by 2020, more than a third of the desired core skill sets of most occupations will be comprised of skills that are not yet considered crucial to the job today...." (Schwab and Samans 2016). Primary drivers of this growing irrelevance include the transience of knowledge, skills and expertise in the era of the Fourth Industrial Revolution (4IR), the unpreparedness and inability of graduates to "hit the ground running" when they enter the workforce, the changing locus of knowledge production (it is estimated that $65 \%$ of knowledge is now generated externally), and a (still) growing number of learning organisations external to the formal university sector (Veldtsman 2019). At a time when 21 st Century graduates need to be contextually relevant, socially mobile, ethical, critical, responsible, adaptable and appropriately equipped to navigate an opaque future, it would seem that the current understanding of knowledge, its creation and dissemination are increasingly out of touch with the lived realities of our societies and our students. 


\section{The Growing Redundancy and Harsh Reality of the Current Business and Delivery Models}

Universities have been impacted by the pandemic in a fundamental manner, challenging notions of their role and function at the most basic levels and laying bare shortcomings which for generations have been ignored, glossed over or remained undetected. The impact of the pandemic on higher education has been quite catastrophic, with many countries reporting the possible loss of the academic year as both staff and students have been sent home, and academic activities moved "online" for continuity. Success has been varied, and responses have been contextually circumscribed. Academics, students and parents have been brought down to earth with a jolt as the realisation of what it means to study "online" hits home. At this unpredictable stage, four realities have emerged and are growing, as the pandemic unfolds:

1. The shocking entrenched and systemic inequalities in education across the world. Even in first world countries, there are glaring inequalities between those who have, and those who don't; in the same communities and in the same institutions. Assumptions made about the capacity and capabilities of students (and staff) to move seamlessly into remote learning environments, and even what it takes to do so, are proving to be woefully out of touch with reality. Many students, even those at ivy league institutions, just don't have the capacity, ability or desire to engage in self-directed learning. Many are electing to take a gap year or to "lose" a year of study, rather than struggle online with what is perceived to be inferior teaching, learning and assessment. The same inadequacies are noted among academic staff, who are genuinely struggling to adapt and cope with the avalanche of work that the remote teaching context encompasses. The issue of access, social justice and equity has thus become an immediate reality for many higher education institutions.

2. The entire world has had to revisit their understanding of "online education", and in that process, their assumptions and shortcomings in their understanding of what this entails, and its complexity, have been revealed. Clearly, online learning means something different to just about everyone who has never practised it before. Many prefer to dub it "remote learning" while still others are now calling it "emergency teaching by remote means," because they have realised that the more traditional Open, Distance and eLearning (ODeL) such as that practised by the University of South Africa (UNISA) and other open universities simply cannot happen overnight. ODeL is a model that takes decades to set up efficiently, and that requires a sophisticated quality assurance model and regime. ODeL has pedagogical and didactical models that differ fundamentally from those in faceto-face universities. With that understanding has come the revelation that many face-to-face teachers and students actively dislike online learning and are simply unable (or they don't want to) cope with it. However, there is consensus that some forms of "online learning" will definitely continue in most universities post COVID-19 (also as a means of ensuring risk mitigation and business continuity), and this may possibly result in exciting new business models emerging in line 
with new realities. The almost mythical belief of online learning, promoted in no small measure by the corporate world, as simply "going online" that is, simply transposing face-to-face learning online, has been shattered.

3. The pandemic has accelerated the process of redefining the university for sustainability. Most would agree that education as we know it is changing fundamentally, and that in order to survive, we will simply have to change our way of doing business. The pandemic has resulted in massive sums of money being lost, for example, in terms of revenue from foreign students and from domestic students who cannot/will not travel, or who can no longer afford education because of changed home circumstances, or because of leadership who have neither the capacity nor the wherewithal to change direction. Reduced income from subsidies and the corporate world (donors) who are now struggling with their own sustainability issues must also be factored into universities' sustainability risks and strategies. Economically, there is little certainty of what will happen, but we are sure that recession is upon us, globally and nationally. We have yet to decipher the impact on finances for our institutions as they are obliged to transform, over the longer term. No doubt some of the benefits of technology, revealed by "remote teaching" will be retained post covid-19, but the predominant sites for creating, producing and disseminating new knowledge have yet to be revealed.

4. The pandemic has brought to the fore many of the issues that ODeL institutions have been working through for years, such as knowledge hegemony and power when it comes to courseware utilisation and development, and the appropriate use of context and language for nation-building and responsible, critical graduates. For many "going online" and making use of online resources, including OERs has brought home the fact that many of these resources are not of local origin and are therefore often contextually inappropriate, even to the extent that they may perpetuate existing stereotypes and prejudices while being out of date and inapplicable in specific work environments. This is an issue of epistemic justice and nation-building which is gaining ground in developing nations and must be addressed.

5. That said, the need for collaborations and agreements has never been greater, but this must be done in a sensitive manner ensuring win-win outcomes. Moving into the future, very few universities will have the means to flourish on their own, with their own resources and capacities. Collaborations and sharing and leveraging of one another's resources and capacities may well become the "new normal," especially where institutions decide to take part of their offerings more fully online.

\section{New Models of Organisational Design and Leadership}

Clearly, most universities must revisit their purpose and their business and leadership models to ensure their relevance and sustainability. The current context demands flexible, integrated and holistic solutions which, for example, may include a greater focus 
on multi-inter and trans-disciplinarity (MIT) and collaboration with other entities such as professional bodies, business and industry in the development of courseware and teaching practice, as well as different modes of student support, assessment and credentialing to meet different societal requirements and student expectations. There is a growing emphasis on the Recognition of Prior Learning (RPL) and the upskilling of mature learners to broaden access and employability. Furthermore, higher education institutions should be open to very fundamental restructuring (operations and administration) to build in the agility needed to adapt quickly to changing contexts.

A different kind of leadership will be needed that truly understands and is able to navigate the complexity and pressures of the prevailing and emerging global and national contexts. Such contexts may extend beyond that for which they have traditionally been responsible (or trained), to include managing the responses and expectations (on the part of staff, students and stakeholders) to socio-economic and political forces globally, continentally and nationally in the best interest of the university; an ever-increasing community of role players and stakeholders all of whom will have their own agendas; and crucially, delivering relevant pedagogy and quality graduates suited to the environment of 4IR.

Leadership will need to be comfortable with pushing the boundaries of transformation and driving the mindset change that is required for a productive workforce and an agile, efficient and effective institution. This presumes an invested academe, that is likely to require reskilling and successful immersion in a new, transformed institutional culture. Academics sometimes oppose change under the guise of sacrosanct academic freedoms, but in truth concerns around marketisation/commercialisation and excessive workloads and administrative demands that come with it are wellfounded and will require innovative, yet sensitive and productive solutions if the sustainability of the institution is taken seriously.

\section{Conclusion}

Higher education is on the cusp of profound transformation, driven by a host of unstoppable socio-economic and political forces. This provides a unique opportunity for universities to pause, reflect and reorient to a "new normal" that will secure their relevance, value and sustainability.

\section{References}

Bennett, R., \& Kent, M. (2017). Massive Open Online Courses and Higher Education: What Went Right, What Went Wrong and Where to Next. New York: Routledge.

Czerniewicz, L. (2018). Unbundling and Rebundling Higher Education in an Age of Inequality. Educause Review, November-D, 10-24. 
Diarra, F. (2004). Diarra, F.D. 2004. IV. Towards New and Re-Emerging Forms of Discrimination? Human Rights Literacy for the Twenty-First Century (Translated from Paul Robert, L'Atlas géopolitique et culturel du Petit Robert des noms propres (Paris, 2000:108)

Nybom, T. (2012). The Disintegration of Higher Education in Europe, 1970-2010: A PostHumboldtian Essay. In S. Rothblatt (Ed.), Clark Kerr's World of Higher Education Reaches the 21st Century: Chapters in a Special History. (pp. 163-181). Springer Netherlands Retrieved from: https://doi.org/10.1007/978-94-007-4258-1_7 (26.07.2020)

OECD (2015). Why Less Inequality Benefits All, OECD Publishing, Paris. The New Zealand nursing journal, Kai tiaki. 84, (1). OECD. Retrieved from: https://doi.org/10.1787/9789264235120-en (26.07.2020)

Palinkas, J. (2013). The Difference Between Change and Transformation. CIO Insight. Retrieved from: https://www.cioinsight.com/it-management/expert-voices/the-difference-betweenchange-and-transformation (26.07.2020)

Schwab, K., \& Samans, R. (2016, January). Global Challenge Insight Report?: The Future of Jobs. World Economic Forum, 1-167. Retrieved from: https://doi.org/10.1177/1946756712473437 (26.07.2020)

Veldtsman, T. H. (2019). Higher education institutions need to face up to the future. Mail and Guardian. Retrieved from: https://mg.co.za/article/2019-06-28-00-higher-educationinstitutions-need-to-face-up-to-the-future/ (26.07.2020)

Mandla S. Makhanya is Principal and Vice-Chancellor of the University of South Africa and President of the Higher Education Teaching and Learning Association (HETL) - International Body. He is past President of the International Council for Distance Education (ICDE) and is also Treasurer of the African Council for Distance Education (ACDE). He is a Deputy Chairperson of the South African National Commission for UNESCO and Chairperson of the Culture Sector of the South African National Commission for UNESCO.

Open Access This chapter is licensed under the terms of the Creative Commons Attribution 4.0 International License (http://creativecommons.org/licenses/by/4.0/), which permits use, sharing, adaptation, distribution and reproduction in any medium or format, as long as you give appropriate credit to the original author(s) and the source, provide a link to the Creative Commons license and indicate if changes were made.

The images or other third party material in this chapter are included in the chapter's Creative Commons license, unless indicated otherwise in a credit line to the material. If material is not included in the chapter's Creative Commons license and your intended use is not permitted by statutory regulation or exceeds the permitted use, you will need to obtain permission directly from the copyright holder. 